\title{
Scientometric Analysis: University Hospital Versus University College of Medicine
}

\author{
Abraar Muneem ${ }^{1}$, David R. Hallan ${ }^{2}$, Sage Gee ${ }^{3}$, Sathvik Saineni ${ }^{4}$, Usman Asad ${ }^{5}$, Surav M. Sakya ${ }^{1}$ \\ 1. Medicine, Penn State College of Medicine, Hershey, USA 2. Neurosurgery, Penn State College of Medicine, Milton S. \\ Hershey Medical Center, Hershey, USA 3. Internal Medicine, Penn State College of Medicine, Milton S. Hershey Medical \\ Center, Hershey, USA 4. Medicine, Gandhi Medical College, Hyderabad, IND 5. Dermatology, St. Anthony Hospital, \\ Oklahoma City, USA
}

Corresponding author: Abraar Muneem, amuneem24@gmail.com

\begin{abstract}
Many medical specialties use scientometrics to assess the impact of publications, journals, and authors. The aim of this study was to analyze and compare trends of publications from a hospital medical center to publications from a college of medicine connected to that hospital and compare collaboration rates between them to other domestic and international institutions. We used Elsevier's SCOPUS database to compare Penn State College of Medicine (PSCOM) publications to Hershey Medical Center (HMC) publications, analyzing 31,856 total publications. We hypothesized that HMC and PSCOM have room to improve on both internal and international collaborations. Our results show that despite PSCOM's international collaboration being nearly three times higher than HMC, overall international collaboration is less than $2 \%$, far below the US national average.
\end{abstract}

Categories: Quality Improvement, Other, Epidemiology/Public Health Keywords: scientometric, penn state, medicine, hershey, medical, center

\section{Introduction}

Scientometrics measures and analyzes scientific literature and is a subset of bibliometrics. Many medical specialties use bibliometrics to compile, use, and review the most-cited works [1]. This is especially useful, as the exponential rise in publications and resources makes it difficult for learners to process information efficiently. It identifies salient topics and assesses the impact of publications, journals, and authors. Furthermore, bibliometrics takes a snapshot in time of objective metrics, which can highlight scientific progression, historical trends, and prolific individuals.

Review began $11 / 17 / 2020$ Review ended 12/08/2020 Published 12/15/2020

\section{○) Copyright 2020}

Muneem et al. This is an open access article distributed under the terms of the Creative Commons Attribution License CC-BY 4.0., which permits unrestricted use, distribution, and reproduction in any medium, provided the original author and source are credited.
The aim of this study was to identify historical trends in Penn State College of Medicine (PSCOM) publications and compare them to the trends of Hershey Medical Center (HMC) publications, especially as it relates to collaboration. We hypothesize that given their physical, financial, and leadership connections, in addition to shared research aims, that the collaboration rate between PSCOM and HMC will be higher than with all other institutions combined, that their top authors and most cited articles will be the same and that they will have similar publication rates in journals. We also hypothesize that international collaboration for PSCOM and HMC will be higher than the national average because of both institutions' focus on global health rotations and research projects.

\section{Materials And Methods}

A comprehensive search within Elsevier's SCOPUS was performed on May 2, 2020. Institution search was performed using the Boolean query "Penn State College of Medicine" and variations yielding Affiliation ID 60027671. Another search was performed using the Boolean query "Milton S. Hershey Medical Center" and variations yielding Affiliation ID 60013671. Data were collected, sorted, and analyzed by topic, affiliation, journal name, highest citations, authors' publications, and H-index. The Penn State Cancer Institute was considered a separate institution. All collaborating affiliations were obtained for both HMC and PSU. Calculated international collaboration rates in percentage were obtained by dividing all publications from international institutions by the total number of publications.

\section{Results}

PSCOM has 18,327 total publications by 4,535 authors, and HMC has 16,259 total publications by 4,135 authors.

\section{Research topics}

For both PSCOM and HMC, the top three publication topics are Medicine (46\% and 57\%, respectively), Biochemistry, Genetics and Molecular Biology (23\% and 19\%, respectively), and Neuroscience (6\% and 6\%, respectively). The bottom three topics for PSCOM were Chemical Engineering (1\%), Multidisciplinary (1\%) 


\section{Cureus}

and Health Professions (1\%), whereas the bottom three topics for HMC were Materials Science (1\%), Chemical Engineering (1\%), and Multidisciplinary (1\%) (Figures 1-2).

Figure 1: Penn State College of Medicine Publications by Topic

\begin{tabular}{|l|l|}
$594,2 \%, 2 \%, 447,2 \%$ \\
$1143,4 \%$
\end{tabular}

FIGURE 1: Penn State College of Medicine (PSCOM) publications by topic

A total of 13 topics were included. The top three topics were Medicine (46\%), Biochemistry, Genetics, and Molecular Biology (23\%), and Neuroscience (6\%). The bottom three topics were Chemical Engineering (1\%), Multidisciplinary (1\%), and Health Professions (1\%).

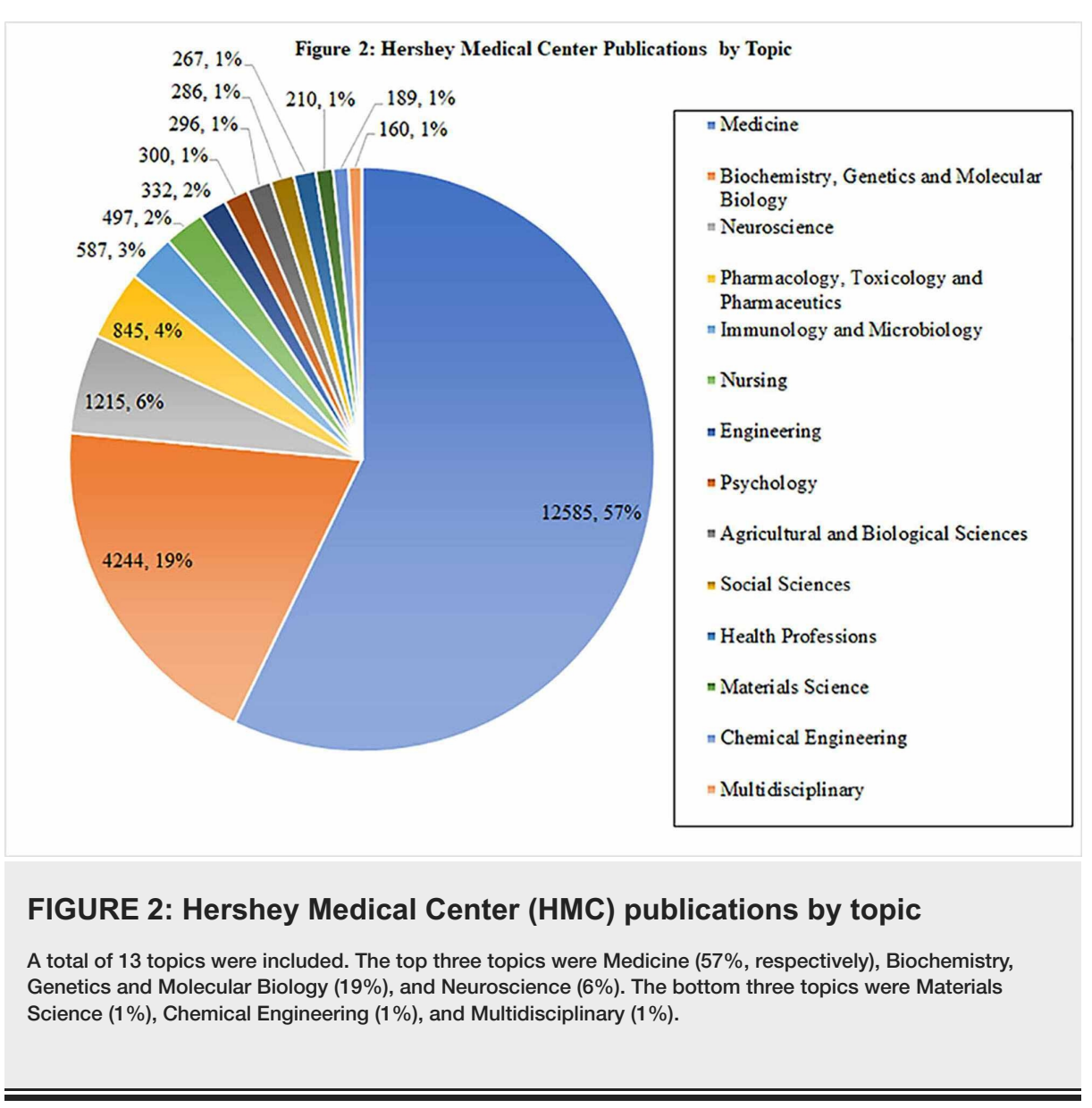

\section{Journals}




\section{Cureus}

The top three journals in which PSCOM published were the Journal of Biological Chemistry (305 publications), Journal of Virology (257), and Cancer Research (156). The top three journals in which HMC chose to publish were the Journal of Biological Chemistry (193), Antimicrobial Agents and Chemotherapy (163), and Cancer Research (140) (Figures 3-4).

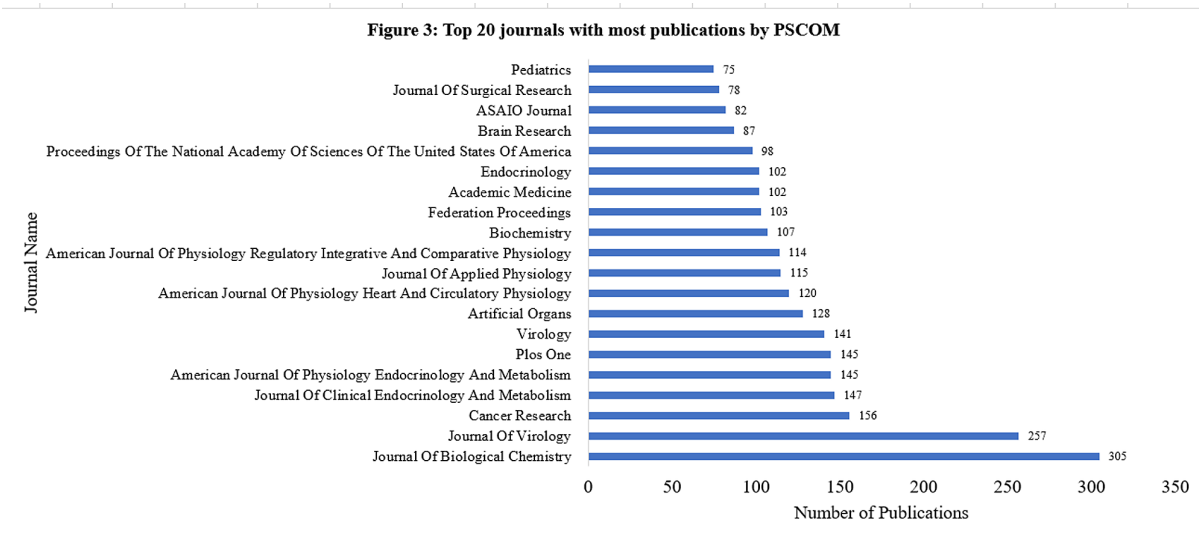

\section{FIGURE 3: Top 20 journals with most publications by PSCOM}

The top three journals were Journal of Biological Chemistry (305), Journal of Virology (257), and Cancer Research (156).

PSCOM: Penn State College of Medicine

Figure 4: Top 20 journals with most publications by HMC

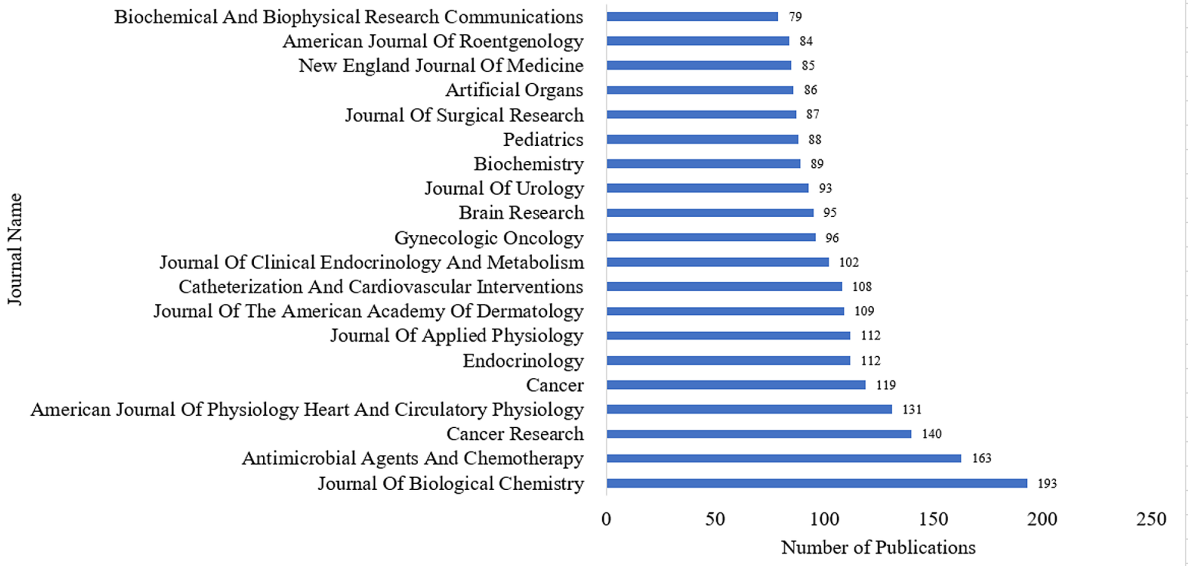

\section{FIGURE 4: Top 20 journals with most publications by HMC}

The top three journals were Journal of Biological Chemistry (193), Antimicrobial Agents and Chemotherapy (163), and Cancer Research (140).

HMC: Hershey Medical Center

\section{Collaboration and affiliation}

Both PSCOM and HMC had one another as their top collaborator at 5,659 publications (Table 1). They also had Penn State University as their second top collaborator, with 2,080 and 1,204 collaborations, respectively. PSCOM's third most common affiliation was with the University of Pennsylvania (397 publications), followed by Harvard Medical School (361). HMC's third most common collaborator was Harvard Medical School (259), followed by the University of Pennsylvania (235). 


\section{Cureus}

\begin{tabular}{|c|c|c|c|c|c|}
\hline \multicolumn{6}{|l|}{ Number of Publications } \\
\hline \multicolumn{3}{|l|}{ Penn State College of Medicine } & \multicolumn{3}{|l|}{ Hershey Medical Center } \\
\hline Affiliation Name & $\begin{array}{l}\text { \# of } \\
\text { Publications }\end{array}$ & $\%$ & Affiliation Name & $\begin{array}{l}\text { \# of } \\
\text { Publications }\end{array}$ & $\%$ \\
\hline $\begin{array}{l}\text { Penn State Health Milton S. Hershey } \\
\text { Medical Center }\end{array}$ & 5,659 & $47.3 \%$ & Penn State College of Medicine & 5,659 & $56.5 \%$ \\
\hline Pennsylvania State University & 2,080 & $17.4 \%$ & Pennsylvania State University & 1,204 & $12.0 \%$ \\
\hline University of Pennsylvania & 397 & $3.3 \%$ & Harvard Medical School & 259 & $2.6 \%$ \\
\hline Harvard Medical School & 361 & $3.0 \%$ & University of Pennsylvania & 235 & $2.3 \%$ \\
\hline Penn State University & 344 & $2.9 \%$ & VA Medical Center & 219 & $2.2 \%$ \\
\hline National Institutes of Health, Bethesda & 324 & $2.7 \%$ & UT Southwestern Medical Center & 219 & $2.2 \%$ \\
\hline $\begin{array}{l}\text { The University of North Carolina at Chapel } \\
\text { Hill }\end{array}$ & 258 & $2.2 \%$ & Case Western Reserve University & 205 & $2.0 \%$ \\
\hline University of California, San Francisco & 256 & $2.1 \%$ & Penn State University & 203 & $2.0 \%$ \\
\hline VA Medical Center & 242 & $2.0 \%$ & Massachusetts General Hospital & 183 & $1.8 \%$ \\
\hline University of Michigan, Ann Arbor & 233 & $1.9 \%$ & $\begin{array}{l}\text { National Institutes of Health, } \\
\text { Bethesda }\end{array}$ & 175 & $1.7 \%$ \\
\hline $\begin{array}{l}\text { University of Pennsylvania School of } \\
\text { Medicine }\end{array}$ & 223 & $1.9 \%$ & $\begin{array}{l}\text { University of Texas MD Anderson } \\
\text { Cancer Center }\end{array}$ & 161 & $1.6 \%$ \\
\hline University of Pittsburgh & 208 & $1.7 \%$ & $\begin{array}{l}\text { University of California, San } \\
\text { Francisco }\end{array}$ & 159 & $1.6 \%$ \\
\hline Johns Hopkins University & 193 & $1.6 \%$ & Cleveland Clinic Foundation & 158 & $1.6 \%$ \\
\hline National Cancer Institute & 179 & $1.5 \%$ & University of Michigan, Ann Arbor & 154 & $1.5 \%$ \\
\hline University of California, Los Angeles & 175 & $1.5 \%$ & Mayo Clinic & 147 & $1.5 \%$ \\
\hline Brigham and Women's Hospital & 172 & $1.4 \%$ & Brigham and Women's Hospital & 140 & $1.4 \%$ \\
\hline Yale School of Medicine & 170 & $1.4 \%$ & Duke University Medical Center & 139 & $1.4 \%$ \\
\hline $\begin{array}{l}\text { University of Texas MD Anderson Cancer } \\
\text { Center }\end{array}$ & 162 & $1.4 \%$ & University of Washington, Seattle & 136 & $1.4 \%$ \\
\hline $\begin{array}{l}\text { The University of Alabama at } \\
\text { Birmingham }\end{array}$ & 159 & $1.3 \%$ & $\begin{array}{l}\text { University of Pennsylvania School of } \\
\text { Medicine }\end{array}$ & 134 & $1.3 \%$ \\
\hline $\begin{array}{l}\text { Columbia University in the City of New } \\
\text { York }\end{array}$ & 159 & $1.3 \%$ & National Cancer Institute & 133 & $1.3 \%$ \\
\hline Total & 11,954 & $100.0 \%$ & Total & 10,022 & $100.0 \%$ \\
\hline
\end{tabular}

\section{TABLE 1: Number of publications by top 20 collaborating affiliations}

Both PSCOM and HMC had one another as their top collaborator in 5,659 publications. They also had Penn State University as their second top collaborator, with 2,080 and 1,204 collaborations, respectively. PSCOM's third most common affiliation was with the University of Pennsylvania (397 publications), followed by Harvard Medical School (361). HMC's third most common collaborator was Harvard Medical School (259), followed by the University of Pennsylvania (235).

PSCOM: Penn State College of Medicine; HMC: Hershey Medical Center

International collaboration rates for both institutes are low [2]. The rate of international collaboration for HMC is $0.71 \%$ (115) and PSCOM is $1.88 \%$ (345).

\section{Citations}


The most cited paper for HMC is "Cardiac-Resynchronization Therapy With or Without an Implantable Defibrillator in Advanced Chronic Heart Failure” by Bristow et al. with 4,278 citations [3]. The most cited paper for PSCOM is "Guidelines for the Use and Interpretation of Assays for Monitoring Autophagy" by Klionisky et al. with 2,462 citations [4].

\section{Authors and patterns of production}

The most prolific author for HMC is Anthony E. Pegg with a total of 588 publications. H-index is a measure of an author's publication productivity and the citation impact of the publication. Dr. Pegg also holds the highest $\mathrm{H}$-index of 88, making him the most impactful and relevant author at HMC. The most prolific author for PSCOM is Vijay K. Varadan with a total of 715 publications. Leonard S. Jefferson holds the highest $\mathrm{H}-$ index of 75 at PSCOM (Table 2).

\begin{tabular}{|c|c|c|c|c|c|}
\hline \multicolumn{6}{|c|}{ Authors by Number of Publications } \\
\hline \multicolumn{3}{|c|}{ Penn State College of Medicine } & \multicolumn{3}{|l|}{ Hershey Medical Center } \\
\hline Author Name & Number of Publications & H-Index & Author Name & Number of Publications & H-Index \\
\hline Varadan, Vijay K. & 715 & 53 & Pegg, Anthony E. & 588 & 88 \\
\hline Amin, Shantu G. & 448 & 59 & Appelbaum, Peter Colin & 419 & 67 \\
\hline Demers, Laurence M. & 440 & 68 & Lipton, Allan M. & 388 & 77 \\
\hline Scott, Ingrid Ursula & 417 & 68 & Rapp, Fred D. & 371 & 36 \\
\hline Legro, Richard S. & 391 & 71 & Connor, James R. & 331 & 75 \\
\hline Wu, Rongling & 381 & 39 & Naccarelli, Gerald V. & 272 & 46 \\
\hline Belani, Chandra P. & 372 & 59 & Mailman, Richard B. & 259 & 51 \\
\hline Lang, Charles & 368 & 63 & Naeye, Richard L. & 245 & 54 \\
\hline Chinchilli, Vernon M. & 365 & 66 & Schmitz, Kathryn H. & 238 & 60 \\
\hline Zagon, lan S. & 333 & 51 & Sinoway, Lawrence l. & 212 & 49 \\
\hline Jefferson, Leonard S. & 315 & 75 & Gilchrist, Ian C. & 210 & 28 \\
\hline Lee, Peter Allen & 314 & 54 & Wu, Jang Yen & 198 & 56 \\
\hline Vesell, Elliot S. & 311 & 46 & Ruffin Iv, Mack Thomas & 196 & 41 \\
\hline Kimball, Scot R. & 296 & 70 & Wang, Kelin & 195 & 55 \\
\hline Undar, Akif & 294 & 33 & Graham, William P. & 175 & 24 \\
\hline Raman, J. D. & 290 & 50 & Ehrlich, H. Paul & 172 & 43 \\
\hline Pierce, William S. & 287 & 31 & Zaino, Richard J. & 169 & 56 \\
\hline Dokholyan, Nikolay V. & 285 & 58 & Huang, Xuemei & 167 & 39 \\
\hline Gelenberǵ, Alan J. & 284 & 54 & Hopper, Kenneth D. & 161 & 38 \\
\hline Hollenbeak, Christopher S. & 278 & 39 & Kreider, John W. & 157 & 33 \\
\hline
\end{tabular}

\section{TABLE 2: Top 20 authors by the number of publications}

The most prolific author for HMC is Anthony E. Pegg with a total of 588 publications. $\mathrm{H}$-index is a measure of an author's publication productivity and citation impact of the publication. Dr. Pegg also holds the highest $\mathrm{H}$-index of 88 making him the most impactful and relevant author at HMC. The most prolific author for PSCOM is Vijay K. Varadan with a total of 715 publications. Leonard S. Jefferson holds the highest $\mathrm{H}$-index of 75 at PSCOM.

\section{Discussion}

The most notable finding from our data analysis is the low international collaboration rate in both institutions (HMC 0.71\%, PSCOM 1.88\%). In the 2020 Indicators Report published by the National Science Foundation, 39\% of US peer-reviewed publications have international collaborators, with China being its 
closest collaborator, followed by the United Kingdom [2]. Previous studies have shown that collaboration with international researchers significantly improved the quality and quantity of research publications as judged by the impact factor of the journals where the works were published, especially in developing countries [5-6]. Dakik et al. 2006 reiterated this finding and found that their institution, the American University of Beirut, had a 9\% international collaboration rate [7]. International collaborations have also been shown to increase the impact of research, as measured by citations [8]. Ranking 23rd of top national research institutions in expenditure, HMC and PSCOM have the potential to improve in international collaborations as well as in collaborations with institutes in developing countries [9].

In the process of improving international collaboration, some factors might explain the potential obstacle to reach a higher international collaboration rate. The Penn State system is a public institution with most of the research activity being federally funded, and it is subjected to federal government regulations for international research collaboration. The complicated approval process of the international component might hinder HMC and PSCOM's motivation for international collaboration [10].

PSCOM and HMC share an organic connection and geographical proximity. Yet, of their combined 31,856 publications, only 5,659 (17.7\%) were collaborative works between these two institutions ( $\mathrm{p}$-value $<0.00001$ ). This is surprising given the graduate student workforce available to PSCOM, which consists of many MD and $\mathrm{MD} / \mathrm{PhD}$ students who also have clinical duties at HMC, and the number of HMC physicians who hold professorship positions at PSCOM.

The most prolific authors from each institution are likewise dissimilar, as are the most cited works. Likewise, although the top journals that PSCOM and HMC publish in are similar, they are not the same and have different rates of publication ( $\mathrm{p}$-value $<0.00001$ ).

Overall, all of our null hypotheses are not rejected, as our analysis provides data contrary to our hypotheses that given their physical, financial, and leadership connections, in addition to shared research aims, that the collaboration rate between PSCOM and HMC will be higher than all other institutions combined, that their top authors and most cited articles will be the same, and that they will have similar publication rates in journals, as well as data contrary to international collaboration being high.

Our limitations include our search being limited to articles contained within Elsevier's database, which, although fairly comprehensive with 70,000 institutional profiles and 1.4 billion cited references, does not capture the entirety of everything ever published. In addition, though we report 5,659 collaborative papers, this number may be lower because one author may have affiliations at both PSCOM and HMC. This stresses the need for more collaboration.

\section{Conclusions}

This study provides a snapshot in time of PSU and HMC publication statistics. Both institutions are producing high-quality research published in top national scientific journals. However, both institutions should make it their goal to foster greater international collaboration as well as collateral collaboration, as an average of $1.30 \%$ international collaboration is significantly lower than the US publication average and is not reflective of the Penn State system's research potential. A 17.7\% collaboration rate between sister institutions that share similar goals and climates is likewise something that can be improved upon. The authors suggest that this study be repeated for other sister institutions throughout the US to compare collaboration rates. This study should also be repeated every few years to note trends and measure efforts to improve collaboration.

\section{Additional Information \\ Disclosures}

Human subjects: All authors have confirmed that this study did not involve human participants or tissue. Animal subjects: All authors have confirmed that this study did not involve animal subjects or tissue. Conflicts of interest: In compliance with the ICMJE uniform disclosure form, all authors declare the following: Payment/services info: All authors have declared that no financial support was received from any organization for the submitted work. Financial relationships: All authors have declared that they have no financial relationships at present or within the previous three years with any organizations that might have an interest in the submitted work. Other relationships: All authors have declared that there are no other relationships or activities that could appear to have influenced the submitted work.

\section{References}

1. Mohammed MF, Marais O, Qureshi AI, et al.: The top 100 most-cited articles in stroke imaging: a bibliometric analysis. Curr Probl Diagn Radiol. 2018, 47:161-167. 10.1067/j.cpradiol.2017.06.003

2. National Science Board, National Science Foundation. Science and Engineering Indicators. Publication output: U.S. trends and international comparisons. (2019). https://ncses.nsf.gov/pubs/nsb20206/.

3. Bristow MR, Saxon LA, Boehmer H, et al.: Cardiac-resynchronization therapy with or without an implantable defibrillator in advanced chronic heart failure. N Engl J Med. 2004, 350:2140-2150. 10.1056/NEJMoa032423 


\section{Cureus}

4. Klionsky DJ, Abdelmohsen K, Abe A, et al.: Guidelines for the use and interpretation of assays for monitoring autophagy (3rd edition). Autophagy. 2004, 12:1-222. 10.1080/15548627.2015.1100356

5. Halstead SB, Tugwell P, Bennett K: The International Clinical Epidemiology Network (INCLEN): a progress report. J Clin Epidemiol. 1991, 44:579-589. 10.1016/0895-4356(91)90222-u

6. Chandiwana S, Ornbjerg N: Review of north-south and south-south cooperation and conditions necessary to sustain research capability in developing countries. J Health Popul Nutr. 2003, 21:288-97.

7. Dakik HA, Kaidbey H, Sabra R: Research productivity of the medical faculty at the American University of Beirut. Postgrad Med J. 2006, 82:462-464. 10.1136/pgmj.2005.042713

8. Sugimoto CR, Robinson-Garcia N, Murray DS, Yegros-Yegros A, Costas R, Larivière V: Scientists have most impact when they are free to move. Nature. 2017, 32:29-31. 10.1038/550029a

9. National Science Board, National Science Foundation. Higher education R\&D expenditures increased $4.7 \%$, exceeded $\$ 75$ billion in FY 2017 InfoBriefs. (2018). https://www.nsf.gov/statistics/2019/nsf19302/.

10. Miller A, Ziad-Miller A: United States federal government regulation of international research collaborations: what every physician-scientist should know. Int I Crit Illn Inj Sci. 2019, 9:5-10. 10.4103/ijciis.ijciis_63_18 